\title{
DEVELOPMENT OF A DISASTER RISK PROFILE IN THE PUBLIC HEALTHCARE SYSTEM DURING FLOOD SITUATION: A CASE STUDY OF NAKHON SAWAN CITY MUNICIPALITY, NAKHON SAWAN PROVINCE, THAILAND
}

\author{
KODCHAKORN KRUTPHONG ${ }^{1}$, JING TANG ${ }^{1,2,3}$ \& NATT LEELAWAT ${ }^{1,3,4}$ \\ ${ }^{1}$ Risk and Disaster Management Program, Chulalongkorn University, Thailand \\ ${ }^{2}$ International School of Engineering, Chulalongkorn University, Thailand \\ ${ }^{3}$ Disaster and Risk Management Information Systems Research Group, Chulalongkorn University, Thailand \\ ${ }^{4}$ Department of Industrial Engineering, Chulalongkorn University, Thailand
}

\begin{abstract}
The United Nations Office implemented the disaster risk profile idea for disaster risk reduction as one of the tools in the development and country's disaster risk reduction. Due to the worldwide agreement, the Sendai Framework of Disaster Risk Reduction 2015-2030 has one of the priority actions to understand the risk before taking further steps to plan and operate. Furthermore, the knowledge of the emergency management has the topic of the critical infrastructure that needs to be protected to make it operate as usual during the emergency to prevent the worst case. The public healthcare system is one of these critical infrastructures. This research followed this concept and focused on the disaster problem in Thailand, which its major disaster type is a flood. The data from the Department of Disaster Prevention and Mitigation, Ministry of Interior, reported that during the fiscal year of 2010-2019, 48,543 THB of government expenditure on the emergency help cost was used to ease the flood disasters. Thus, this research paid attention to the development of the disaster risk profile in the public healthcare system during the flood situation. The study area was Nakhon Sawan Municipality, Nakhon Sawan Province, Thailand, one of the significantly affected areas from the 2011 Thailand floods. The main target referred to the operation during the 2011 floods in the study area. This research applied the BPMN 2.0 to understand the operation process and the cooperation during the flood situation. The model could explain the function and responsibility of each organization and the disaster risk profile, by focusing on the operational level during the flood situation. The outcome of this was the risk profile and the suggestion to conduct the policy in the next step.
\end{abstract}

Keywords: risk profile, flood, public health, emergency operation, Thailand.

\section{INTRODUCTION}

The United Nations office implemented the disaster risk profile idea for disaster risk reduction (UNDRR) as one of the tools in the development of country's disaster risk reduction [1]. From the beginning, of the vision of the sustainable development of the international agreements on a lead of the United Nations, in the field of disaster risk reduction, the international community has the decision to create the shared framework in the name of Sendai Framework of Disaster Risk Reduction 2015-2030 [2]. This framework has the priority of the Disaster Risk Management in each country in the government policy for the relation in the wider area.

At the global level, the World Health Organization (WHO) Regional Office for Europe states that "floods are the most common natural disaster" [3]. And the data from the same organization also states that 
"Floods can cause widespread devastation, resulting in loss of life and damages to personal property and critical public health infrastructure. Between 1998 and 2017, floods affected more than 2 billion people worldwide".

According to the recent research, not only countries in Europe were affected by floods, but also those in Asia. It was stated that "analysis of flood trends in Asia shows that flood disasters in most of the Asian countries are increasing significantly, especially in the last few years Asia witnessed a rapid increase of flood disasters" [4].

In Thailand, the data from the Department of Disaster Prevention and Mitigation (DDPM), showed that in 10 years, between 2001-2012, there were 189 times of flood disasters. The other source collecting data between 1989-2009 (20 years) revealed that Thailand faced 213 flood disasters which resulted in 115,786.67 million Baht of damage cost. In particular, according to "2011 Great Flood: the lesson from the experience" [5] affected the area of 57,600 square kilometers in 65 provinces. There were approximately 12 million victims and 815 deaths from the incident. The calculated damage cost in the economic sector was 1.425 trillion Baht, seven times more than the government budget in that year. This great flood disaster did not affect only Thai people or business, but also the supply chain because of the flood in Rojana Industrial Park, Ayutthaya, and other industrial parks. The information from the Bank of Thailand showed that the damage cost from seven industrial parks in Ayutthaya and Pathum-thani was approximately 24 billion Baht. The data from Thailand's Land development department also showed that from 2009 to 2019, there were three levels of the chronic flood area in Thailand: 8-10 times, 6-7 times, and less than three times. Most of the areas with 8-10 times of the chronic flood were in the lower northern and the central parts of Thailand [6]. According to the budget report in the section of government cash advance from DDPM in 10 years between 2010-2019 (Fig. 1), the governors had submitted the request for the advance payment during the emergency situation in the flood disaster section every year, with the highest in 2012, the year after the great flood. Thus, this information showed the minimum damage cost that came from flood disasters each year. It also displayed the delay of the budget and the disaster period because the local government needed to pay first during the situation before submitting the request for the related organization's budget and the number of the provinces affected by the flood disasters in the past decade.

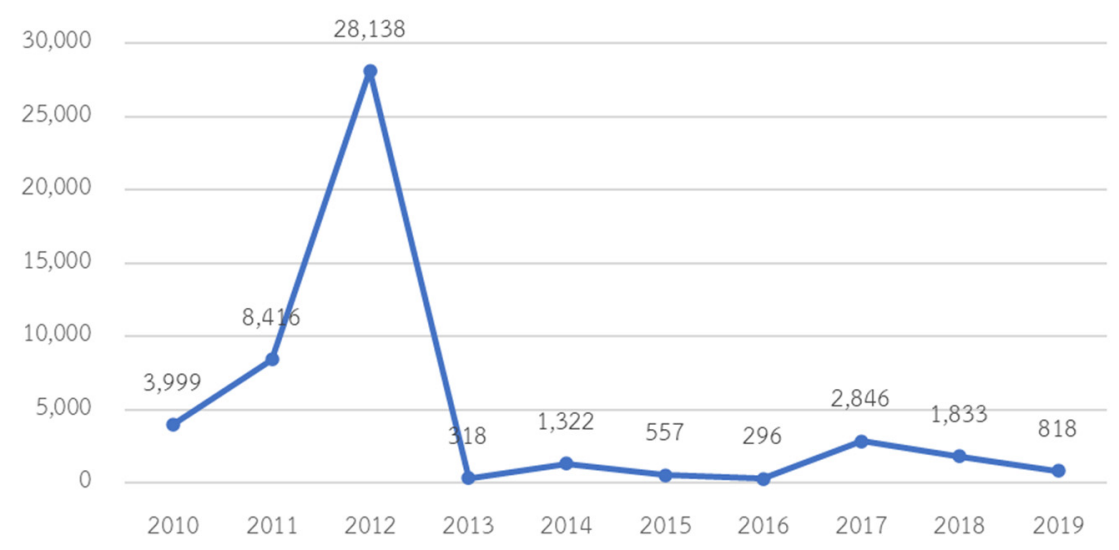

Figure 1: Show the amount of flood situation emergency compensation cost (million Baht) in Thailand from DDPM budget report in 10 years (2010-2019). 
The idea of the critical infrastructures during the emergency made this operating system more important. With regard to this field of knowledge, during the emergency the critical infrastructures needed to be protected to prevent the worse effect from the disaster [7]. The damage to the public healthcare system from the synopsis of Thai cabinet in 2010 flood disaster [8] stated that the damage cost of hospitals was 50.3 million Baht, with number of deaths and injuries. During the 2011 great flood, the effect was more severe due to the wider flooded areas. The learning from disaster management and emergency management mentioned the critical infrastructures and key assets during the disaster. These critical infrastructures are based on basic human needs. If the government, both at the local and the national levels cannot manage these infrastructures properly, they could cause the disaster. Moreover, if the infrastructures could not operate as usual during the disaster, the situation could get worse. Healthcare and Public Health are one of the most crucial factors because the "health sector plays a significant role in response and recovery across all other sectors in the event of a natural or manmade disaster" [7]. Thus, from the perspective of disaster management, it is important to maintain the critical infrastructures before the disaster happens in the preparation phase.

The disaster risk profile is one of the tools of disaster risk management. This tool has been widely implemented with the support of UNDRR. It is seen as an important tools to use in the disaster risk assessment process in several countries and in different dimensions such as economics, social, environment, etc. The risk assessment is inside the whole process of disaster management that can be conducted at any level, either a small or a big scale. The Sendai Framework for Disaster Risk Reduction 2015-2030 has the aspect of the "understanding disaster risk is the priority for action" [2]. However, with the complexity of the guideline the level that frequently implements is at the national level or wider, after the process with a national disaster risk profile as the product of the assessment. The national government would get the resources of the policy planning process in the future along with scientific information of the disaster risk that has the expected benefit for the policy management. !

\section{RESEARCH METHODOLOGY}

This research started with the review the operation system review during the flood situation by examining and conducting the interviews regarding to the great flood in 2011 . The next step was to visualize the operation system details by creating a diagram of Business Process Modelling Notation (BPMN 2.0). Finally, the stakeholder analysis was conducted to find the relations of the public healthcare system and related organizations during the flood.

\subsection{Operation system visualization}

This part of the research was conducted by reviewing and interviewing about the 2011 great flood operation in Nakhon Sawan city municipality. It covered both the municipality and the hospital (Sawan Pracharak hospital). It visualized the operation system and assessment for the interconnection between the numerous organizations inside this area, especially the public healthcare system related organizations. The data collection to create the diagram focused on the operation of Sawan Pracharak hospital, as this hospital is the main hospital in the municipality and other parts of the province. The situation resulted in the increasing number of patients in the hospital and caused the disruption to operational activities at the same time. Therefore, the complexity of the operation during this specific situation caused by the separation of work by the related organizations, the separated commanders, and the 
command systems conducted. It was a common situation that happened during the management that involved numerous stakeholders [9].

The visualization concept and model were conducted using Business Process Modelling Notation (BPMN 2.0) to show the details of the operation and the cooperation between related organizations during the flood situation. BPMN 2.0 is "the graphical notation will facilitate the understanding of the performance collaborations and business transactions between the organizations" [10]. Thus, this model showed the details of the operational activities that were essential for the public healthcare system during the flood situation or other disasters.

\subsection{Stakeholders' analysis}

After reviewing the details of the operation from BPMN 2.0 diagram, this part conducted the stakeholders' analysis which its concept "is the key to understanding the complex relationships among all the parties involved" [11]. The next step was to conclude all of the previous processes and show the responsible organizations and their ministries. The outcome was to map the interrelation between the organization both at the local and national levels. Afterwards, the previous diagram was brought in to break into the figure and the factor to show the responsible organizations by the risk equation 123 .

$$
\text { Risk }=\frac{\text { Hazard } \times \text { Vulnerability }}{\text { Capacity }}
$$

This equation shows the factors which create the risk and their effects with the level of risk. The multiplier factors, hazard, and vulnerability are the factors that increase the risk by its number/value. However, the factor with the inverse effect to the risk level is the capacity, as the higher capacity will decrease the risk value. These factors are also able to display the healthcare system risk by calculating the vulnerability of the operation, activity, and the capacity of the operation to show how well it could cope with the hazard and vulnerability.

\section{FINDINGS}

From the research methodology, the findings would be present, starting with the operation system diagram referred to the BPMN 2.0 concept, to show the details of the operation during the flood situation, following by the stakeholders' analysis and the risk factors developed from the first diagram and the analysis.

\subsection{Flood operation system details diagram}

After the data collection process regarding the information profile of the study area, the diagram by the concept of BPMN 2.0 was created and divided into two areas, i.e. Nakhon Sawan municipality and the public healthcare system (Sawan Pracharak hospital and other hospitals) as shown in Figs 2 and 3. After that, the stakeholder's analysis from this cooperation process during the flood situation was done.

First, Fig. 2 showed the operation of the Nakhon Sawan municipality during the 2011 great flood. The event diagram started with the flood risk season, in Fig. 2(a) that was highlighted. The municipality management board or the mayor ordered the engineering department to monitor the situation and to report the situation back to the management sector of the municipality to make a public announcement. Meanwhile, the operation and management team of Sawan Pracharak hospital prepared the responses to operate during the flood situation. Then, the triggered event occurred, the dam failure, resulting in Nakhon 


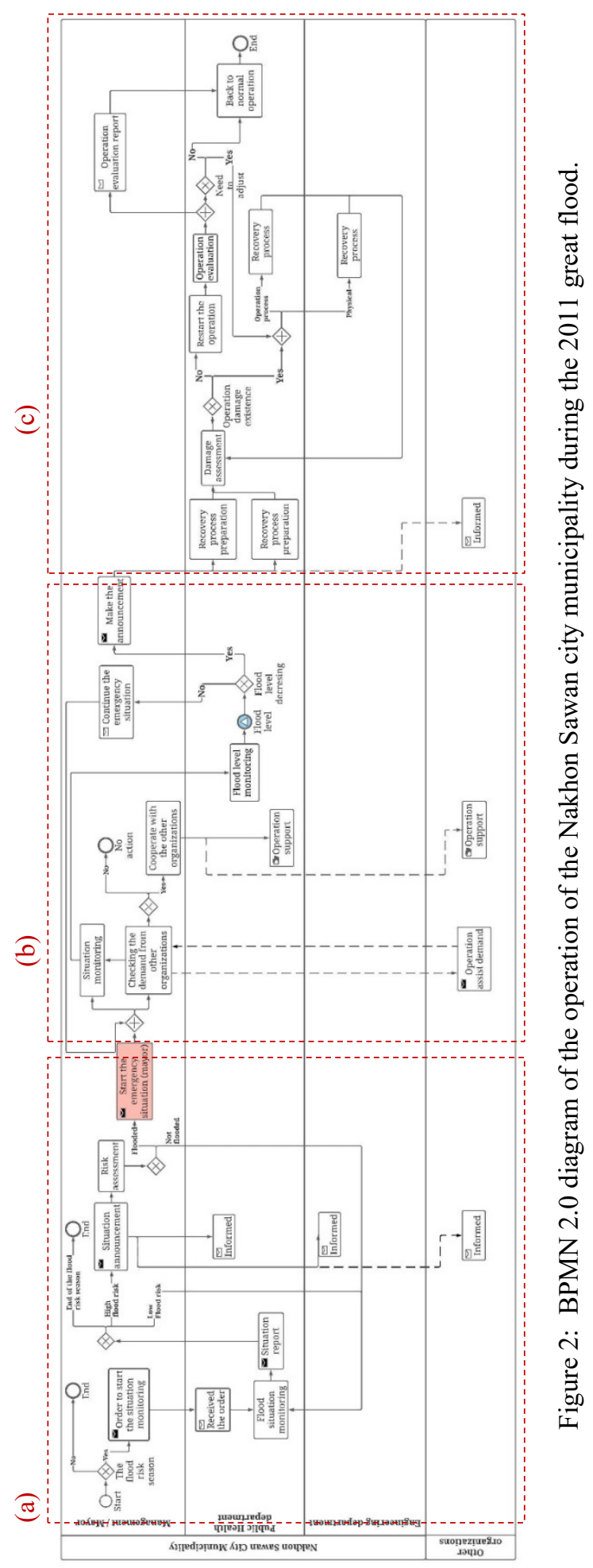




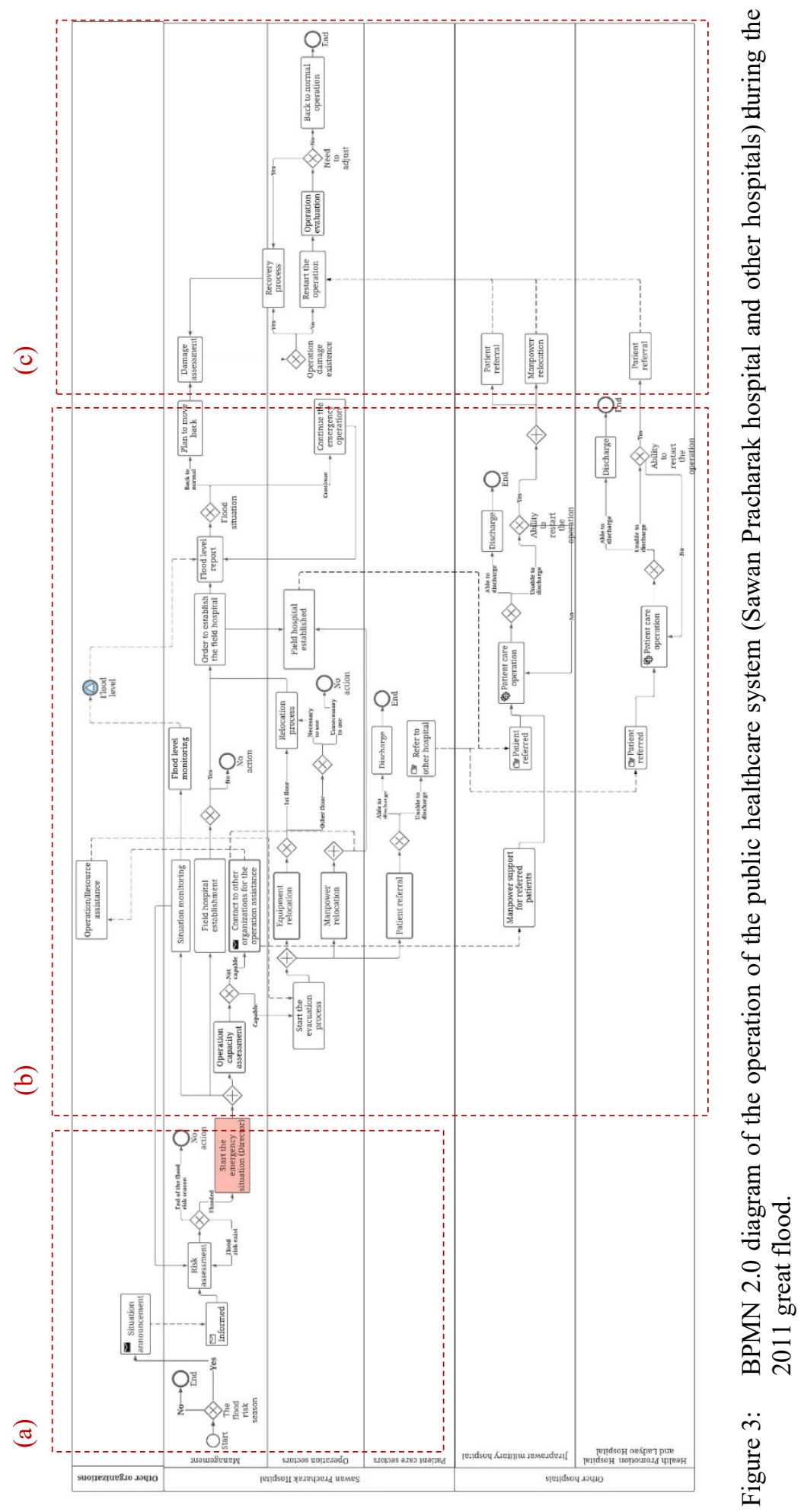


Sawan city flood. Thus, the management section, with the mayor as the commander, needed to announce to make a public announcement to declare the emergency. The declaration of emergency would be done only if the flood occur.

As shown Fig. 2(b), it showed the operating system after the emergency situation in the municipality. This operation started with the parallel monitoring and the cooperation with the other organizations. As the support role during the flooded period, they also monitored the flood level until it decreased to the proper level to conduct the recovery phase, then they made another announcement. The last part of the operation was in Fig. 2(c), the recovery operation. They started with the damage assessment. The damage were separated into two kinds. The first one is the physical damage which the engineering department was responsible. The latter is the operation damage in the public healthcare service which the public health department was in charge. Both of the recoveries needed to redo the assessment until every section could work as usual before the end of the operation.

The public healthcare service operation system diagram was shown in Fig. 3. The start of the operation was in Fig. 3(a), similar to the municipality's activities. This part was the hospital director's decision, as the emergency commander, to make the emergency announcement. In Fig. 3(b), the top priorities during the emergency were the patient referral and the establishment of field hospitals. Firstly, they separated the patients into two groups, dischargeable patients and non-dischargeable patients at that time. The patients who were not well enough to discharge needed to be referred to the other hospitals; Jiraprawat military hospital, Health promotion hospital, and Ladyao hospital. The relocation process was assisted by the municipality and the military camp. During the operation, at Jiraprawat military, the IPD (in-patient departments) of the field hospital had been set up. It is still operating after the flood situation. During the whole process, the management sector ordered involved departments to monitor the flood level and the situation then made the announcement and took the next step of the operation planning.

After the flood level decreased to the normal condition, as seen in part (c) the hospital also conducted the damage assessment to do the recovery process and prepared for the usual operation. For the referred patients and staff, the relocation operation back to the Sawan Pracharak hospital was conducted by the commander. However, before the normal operation restart, the hospital and the municipality had to assess the damage both operational and physical damage from the flood. After the recovery and the assessment were accomplished, the operation went back to normal again.

\subsection{Stakeholders' analysis and list of risk infrastructure}

As shown in Figs 2 and 3, the operation in two parts of the organization was separated by the BPMN 2.0 diagram with different commands and orders. However, in reality, they collected data showed that these two operation systems had interdependency during the flood situation. Therefore, this research needed to conduct the stakeholder's analysis to link these operation details together.

After showing the details of the operation during the flood situation, the government played the main role during the disaster to conduct the cooperation. Fig. 4 displayed the stakeholders' analysis diagram divided by the responsible ministries i.e., Ministry of Interior, Ministry of Public Health, and Ministry of Defense. As shown in Fig. 4 The Public Healthcare Service is the organization under the Ministry of Public Health, while the other organizations assisted the operation such as the Provincial Administrative Organizations (PAO) which is under the Ministry of Interior. They distributed the public area under their authority to use for the field hospital. In Fig. 5, existing resources that could support the operation of the 
public healthcare system were shown. From the government sector, a column of hazard were the ability to monitor the natural hazard and the ability to forecasting. The vulnerability column was to show the facility which could be disrupted during the disaster. Flooding was the government and public healthcare sector's co-responsibility. It could be concluded that the operational activity of the healthcare sector needs to be supported by the government sector (city municipality, PAO, etc.).

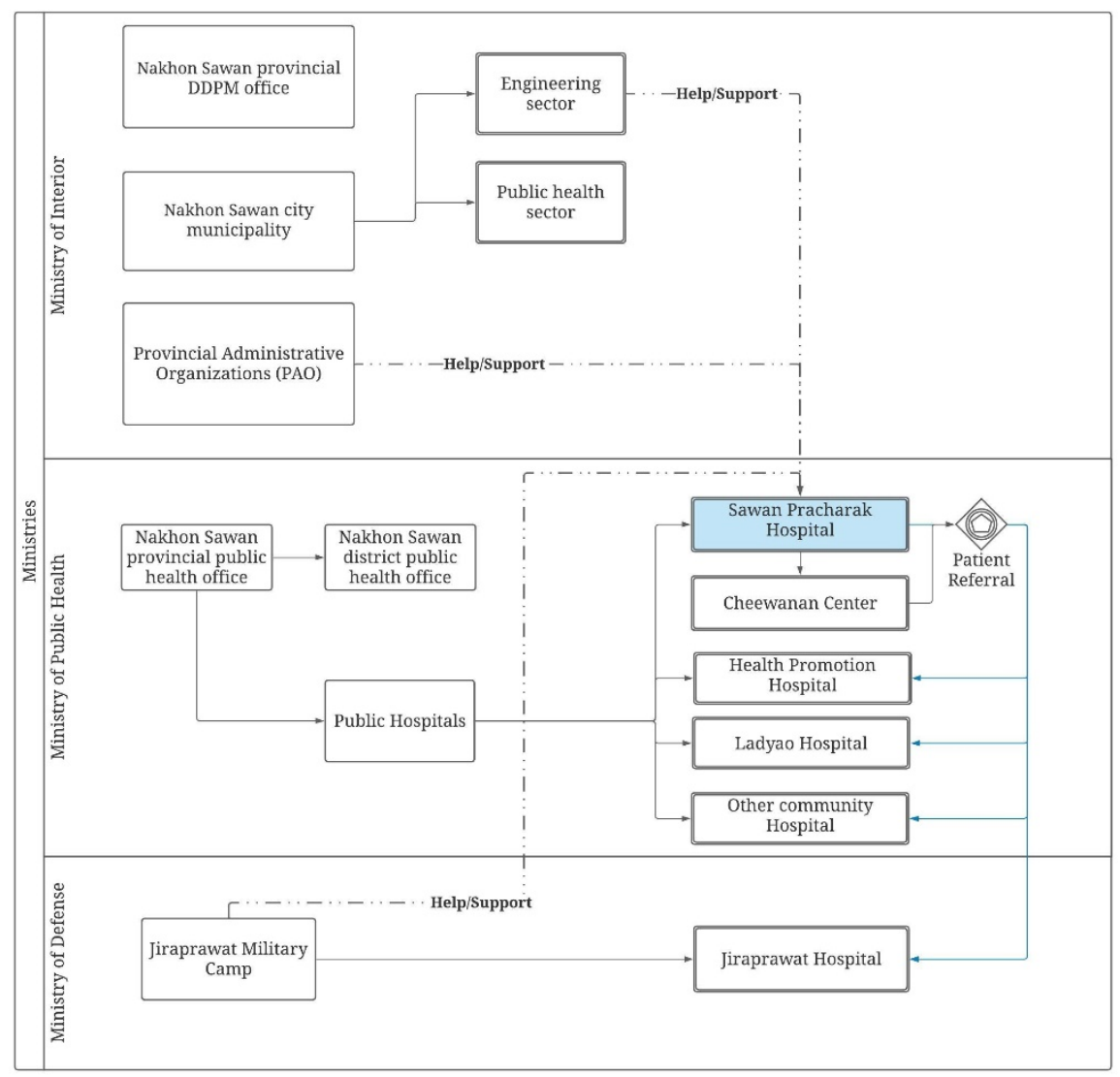

Figure 4: Diagram of stakeholders' analysis during the flood situation.

\section{CONCLUSION}

The conclusion of the research from the risk profile data assessment found the interconnection and the cooperation pattern of the organizations inside the area of Nakhon Sawan city municipality during the flood. The model was visualized from the previous disaster, the 2011 great flood in Thailand, and the operation during that time. As shown in previous figures, the operation condition was altered during the disaster and emergency as the capability of the organizations and the hospitals was exceeded. Thus, the interconnection to assist the operation needed to be conducted. 


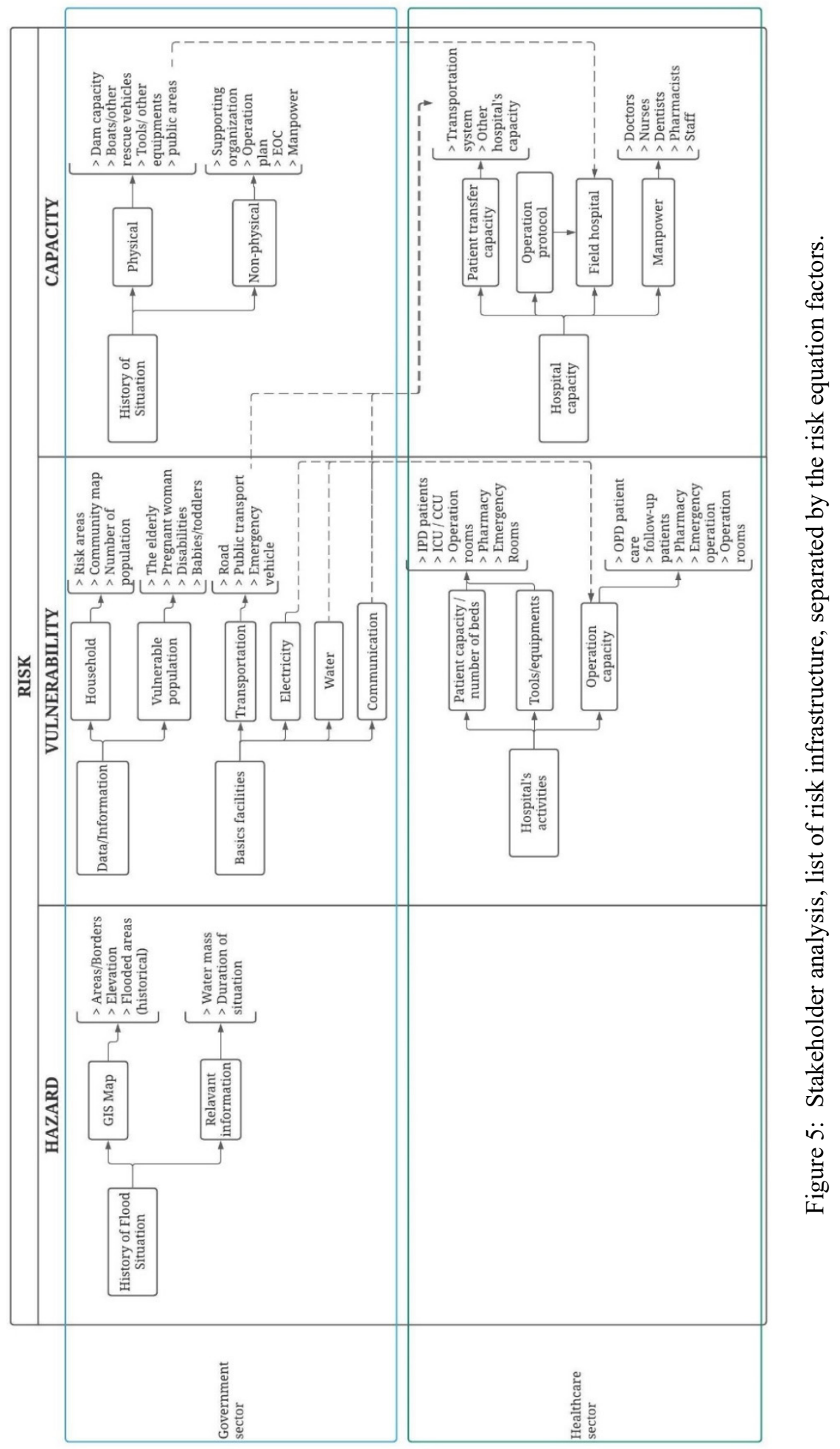


In this research, which focused on the operation of the public healthcare system after the assessment, the details of the basics facilities responsible by the government sector needed to be secured for the continuity of the public healthcare system, as included in the critical infrastructures [7]. When the assessment showed the over operation capacity and limited ability of the hospitals during the emergency, further assistance would be requested from the other government organization, both the government sector (municipality, PAO) and the military sector. The risk profile was created to gather the data and information from the responsible organizations and separated the data by the risk equation factors. The relation diagram would help those in the policy management level and the commanders to have the idea to contact the right organizations during the incident.

For further research, after creating the risk profile, the interviews with the specialists in the public healthcare system, the operation staff and the senior government officers should be conducted to gain more insights both in the operation side and the management side. The preference of information during disaster is also interesting to be taken into consideration with the operation analysis [13], [14]. The result of this can support the other area. Also, the outcome of this research will be fundamental to the risk assessment process and the conclusion can support the planning process in the emergency.

\section{ACKNOWLEDGEMENTS}

This research was supported by the Collaborative Research with External Partners (CU CRX2101), Japan International Cooperative Agency (JICA) Project for ASEAN University Network/Southeast Asia Engineering Education Development Network (AUN/SEED-Net).

\section{REFERENCES}

[1] United Nations International Strategy for Destruction Reduction (UNISDR), Words into action guidelines: National disaster risk assessment, special topic: Public communication for disaster risk reduction. United Nations Office for Disaster Risk Reduction, 2017.

[2] United Nations Office for Disaster Risk Reduction (UNDRR), What is the Sendai Framework? https://www.undrr.org/implementing-sendai-framework/what-sendaiframework. Accessed on: 31 Mar. 2021.

[3] World Health Organization (WHO), How flooding affects health. https://www.euro.who.int/en/health-topics/environment-and-health/Climate-change/ news/news/2013/05/how-flooding-affects-health. Accessed on: 31 Mar. 2021.

[4] Dutta, D. \& Herath, S., Trend of floods in Asia and flood risk management with integrated river basin approach. Proceedings of the 2nd International Conference of Asia-Pacific Hydrology and Water Resources Association, 1, pp. 55-63, 2004.

[5] Suriyawongsepaisan, P. (ed.), The Great Flood 2011: Lesson Learn from the Situation. 1st ed., Health System Research Institute (HSRI): Nonthaburi, 2012.

[6] Land Development Department, Map of chronic flood between 10 Years. Land Development Department: Bangkok, 2019.

[7] Fagel, M.J., Principles of Emergency Management and Emergency Operations Centers (EOC), 1st ed., CRC Press: Boca Raton, FL, 2010.

[8] Ministry of Public Health, Report of damage from flood disaster in medical and public health section, 2010.

[9] Kodaka, A., Ono, T., Watanabe, K., Leelawat, N., Chinranapakdee, C., Tang, J., Ino, E. \& Kohtake, N., A dependent activities elicitation method for designing area business continuity management. 2020 IEEE International Symposium on Systems Engineering (ISSE), 2020. 
[10] Object Management Group, Home: BPMN 2.0 charter. https://www.bpmn.org/. Accessed on: 25 May 2021.

[11] Sapapthai, S., Leelawat, N., Tang, J., Kodaka, A., Chintanapakdee, C., Ino, E. \& Watanabe, K., A stakeholder analysis approach for area business continuity management: A systematic review. Journal of Disaster Research, 15(5), pp. 588-598, 2020.

[12] United Nations International Strategy for Destruction Reduction (UNISDR), Hyogo framework for action 2005-2015: Building the resilience of nations and communities to disasters 2005, UNISDR., 2005.

[13] Leelawat, N., Muhari, A., Srivichai, M., Imamura, F. \& Bricker, J.D., Preference for information during flood disasters: A study of Thailand and Indonesia. Sustainable Future for Human Security, ed. B. McLellan, Springer: Singapore, pp. 335-349, 2018.

[14] Leelawat, N., Pee, L.G. \& Iijima, J., Mobile apps in flood disasters: What information do users prefer? Proceedings of the 12th International Conference on Mobile Business, 2013. 